\title{
Developing Strategies and Current Trend of Smart Factory
}

Author(s): Bong Joo Jeong, June-Young Bang

Source: Journal of International Logistics and Trade 2018; 16(3):88-94

Published by: Jungseok Research Institute of International Logistics and Trade, Inha University

DOI: https://doi.org/10.24006/jilt.2018.16.3.088

The Journal of International Logistics and Trade is an official journal published by Jungseok Research Institute of International Logistics and Trade, Inha University, Korea. JILT welcomes manuscripts that advance the practice and science of logistics, trade, and other related fields.

Frequency: Quarterly (March, June, September, December)

Stable URL: https://www.ejilt.org

The Jungseok Research Institute of International Logistics and Trade is a specialized academic research institute representing Inha University and the Inha Foundation in Korea. The institute aims to become a representative institute in Northeast Asia in the research of logistics and trade.

Stable URL: https://jrieng.inha.ac.kr

(C) Copyright. Jungseok Research Institute of International Logistics and Trade.

This is an Open-Access article distributed under the terms of the Creative Commons Attribution NonCommercial License (http://creativecommons.org/licenses/by-nc/4.0/) which permits unrestricted noncommercial use, distribution, and reproduction in any medium, provided the original work is properly cited 


\title{
Journal of
}

\section{International Logistics and Trade}

\section{Developing Strategies and Current Trend of Smart Factory}

\author{
BongJoo Jeong a , June-Young Bang ${ }^{\mathrm{b} *}$ \\ ${ }^{\text {a }}$ Department of Industrial and Management Engineering, Hannam University, Daejeon, Korea \\ ${ }^{\mathrm{b}}$ Department of Industrial and Management Engineering, Sungkyul University, Gyeonggi, Korea
}

\begin{abstract}
ARTICLE INFO
Article history:

Received 31 October 2018

Accepted 17 December 2018

Keywords:

Smart factory

Smart manufacturing

Industry 4.0

Smart technology

ABSTRACT

Smart factory is the most important feature of the fourth industrial revolution in the manufacturing field. In this paper, we introduce smart factory solutions suggested by the major solution providers. Furthermore, we classify solutions by the category of three value-chain activities: product development activity, product manufacturing activity, and sales activity. In addition, the status-of-art and best practices of the smart factory solutions are introduced. To examine the current trends of smart factories, we classified the manufacturing industries into four groups based on two factors: product variety and production volumes, and suggest directions for the successful application of smart factories in each industry group. Finally, we suggest strategies to improve the actual manufacturing competitiveness of factories.
\end{abstract}

\section{Introduction}

Since Klaus Schwab mentioned the Fourth Industrial Revolution at the World Economic Forum in 2016, the concept of smart factory has emerged in the manufacturing industry. From that time, many companies have been developing smart factories. Siemens and GE are leading the push toward the smart factory and are intensively marketing their solutions to the public. These solution providers often advertise that their solutions can deliver "Smart" applications to any factory with little effort and budget. However, to ensure the successful conversion of factories to smart factories, it is necessary to verify whether smart factory solutions are consistent with business performance and product production characteristics.

However, most research on smart factories simply enumerate technologies or cases of smart factory use rather than suggesting strategic approaches. Even the strategic approach presented by the solution vendors is mostly focused on production operations or its IT systems. However, creating a smart factory cannot be explained exclusively using the above two factors. Therefore, it is needed to categorize the solutions according to each activity of the value chain and suggest strategies for solution application to the factory including the priority of solution modules according production processes.

There have been a lot of research since the German firm, DFKI, first mentioned 'smart factory' in 2011. However, many studies have focused on trends of smart technologies to build smart factories or have introduced applications of smart factories. Byun (2016) introduced cases of smart factory application and examined the analysis of smart factory trend. Lu et al. (2017) and Chen et al. (2016) introduced primary technologies to establish a smart factory and introduced various examples. Thoben et al. (2017), Bagozi et al. (2017), Lim et al. (2017), and Park (2017) introduced examples of smart factory and their applications in various industries. While most research focus on smart factory technologies and application examples, research on implementation strategies of smart factories are limited. Zhou et al. (2015) studied how to implement CPS (Cyber physical system) for smart factories, and Kang et al. (2016) discussed research reviews, future research directions and strategies of smart factory. Lee et al. (2017) proposed the future directions of smart factory for small and medium-sized firms.

Although there have been a lot of studies on smart factories, there is a lack of research to classify smart factory

\footnotetext{
* Corresponding author: Department of Industrial and Management Engineering, Sungkyul University-ro 53, Manan-gu, Anyang-si, Gyeonggi-do, 14097, Korea; Email: jybang@sungkyul.ac.kr
} 
solutions according to values they provide. Also, there are few studies on differential implementation strategies of smart factories according to industrial characteristics. Therefore, in Section 2 of this study, smart factory solutions are classified according to values they provide, and directions for establishing smart factories that match the characteristics of each industry are suggested in Section 3. In this paper, we propose two strategic criteria for the various smart factory solutions according to achievement and effectiveness. First, we evaluate and categorize the solutions in terms of performance in the value chain, and then in terms of the effectiveness according to features of the production process.

\section{Strategic value-chain activities of smart factory}

The concept of the smart factory, in a broad sense, can be applied throughout the value chain in which products are designed, developed, manufactured, and delivered to customers. However, many companies have understood the concept only from a narrow perspective such as production processes or the factory itself. Furthermore, many ignore the purpose of smart factory installation and are easily misled by advanced smart factory technologies. From now, we will introduce the technologies and strategies of smart factory.

The Korean government proposed the 8 smart infrastructure technologies in 2015 and have prioritized financial support to develop critical technologies.

Table 1. The 8 smart infrastructure technology (2015, Ministry of Science, Ministry of Industry)

\begin{tabular}{cc}
\hline Technology & \multicolumn{1}{c}{ Roles of technology and detailed applications } \\
\hline Production system innovation & - Factory optimization (Product design, Manufacturing, Energy efficiency, etc.): \\
technology (4) & Smart sensor, Cyber physical system, 3D printer, Energy saving \\
Information and communication & - Collect, processing, applying of data from manufacturing system: \\
infrastructure technology (4) & Internet of things, Cloud, Big data, Hologram \\
\hline
\end{tabular}

The smart technologies listed in Table 1 are necessary to implement and operate the smart factory. However, just the simple application of these technologies cannot guarantee the success of the smart factory implementation and its operation. For these goals, we have to understand what kinds of values are provided by the Smart Factory vendors with their solutions, and which activity of the value chain the solutions provide advantages. From now, we will detail the purpose of the smart factory and the solutions that can be implemented for each activity of a value chain to achieve this purpose.

The essential target of the manufacturing business is to maximize customers' satisfaction and the profit of the enterprise by producing goods (products or services) efficiently, and delivering them to customers at the appropriate time. The value chain from production to customers can be divided into three activities: Product development, Production, and Sales including after-sales-service. Generally, sales activities include the marketing and after-sales-service, but, in this research, we exclude marketing aspects to provide simple understanding about the smart factory.

Table 2. Classification of smart solutions by value

\begin{tabular}{|c|c|c|c|c|}
\hline \multirow{2}{*}{$\begin{array}{c}\text { Value chain } \\
\text { Development }\end{array}$} & \multicolumn{2}{|c|}{ Value } & \multicolumn{2}{|c|}{$\begin{array}{ll}\text { Smart factory solutions } \\
\end{array}$} \\
\hline & $\begin{array}{r}\text { Satisfy } \\
\text { Impro }\end{array}$ & $\begin{array}{l}\text { ustomer needs / } \\
\text { e productivity }\end{array}$ & $\begin{array}{l}\text { Customer needs analysis, } \\
\text { Product lifecycle management }\end{array}$ & Virtual verification \\
\hline \multirow{8}{*}{ Manufacturing } & \multirow{3}{*}{ Increase } & \multirow[b]{2}{*}{ Machine utilization } & Predictive maintenance & Remote control system \\
\hline & & & $\begin{array}{l}\text { Flexible manufacturing system, } \\
\text { Smart production planning }\end{array}$ & Cyber physical production system \\
\hline & & Yield & $\begin{array}{l}\text { Intelligent quality control, } \\
\text { Particle management system }\end{array}$ & Fault detection \& classification \\
\hline & \multirow{4}{*}{ Decrease } & Material cost & Modular design & \\
\hline & & Labor cost & $\begin{array}{l}\text { Intelligent automation, } \\
\text { Smart logistics }\end{array}$ & $\begin{array}{l}\text { Smart working assistant system } \\
\text { Intelligent defect detection }\end{array}$ \\
\hline & & Overhead cost & Green and renewable energy & Energy saving system \\
\hline & & Inventory cost & $\begin{array}{l}\text { Supply chain optimization, } \\
\text { Intelligent warehouse }\end{array}$ & Smart inventory management \\
\hline & \multicolumn{2}{|c|}{ Increase safety \& security } & Smart safety & Smart security solution \\
\hline $\begin{array}{l}\text { Customer service } \\
\text { (A/S) }\end{array}$ & \multicolumn{2}{|c|}{ Value for customer } & $\begin{array}{l}\text { Remote customer support, } \\
\text { Remote monitoring service }\end{array}$ & Prediction in Customer Service \\
\hline
\end{tabular}

In Table 2, we categorize the key solutions of smart factories according to the value delivered to each value chain activity. A solution tends to be designed to provide more than one benefit for different activities of the value chain, so that one solution can be classified into multiple categories. However, solutions were classified into categories that fit their primary purpose of industry. Note that we omitted the detailed descriptions of solutions introduced in Table 2 since they are found in various surveys including Radziwon et al. (2014), Hozdić (2015), Kang et al. (2016), and Yang (2017). 


\subsection{Product development activity}

To support product design activities of value chains, customer needs analysis includes a customer demand analyzer which analyzes the customer's big data. With this analysis, designers associated with the company can reflect the exact requirements of the customer in product design. For example, LG Electronics, one of the major home appliance manufacturer, utilize big data technologies to analyze their voice of costumers (VOC). Based on the results of this analysis, designers have identified the drawbacks of the market leader's existing premium product, removed the drawbacks, and improved products (ex. vacuum cleaner). Virtual verification solutions with virtual reality and 3D simulation technology are also used in production design activities to verify the assemblability and mass production efficiency of new products. Since 2012, GM, the world's leading automobile company, has introduced virtual reality technology to their assembly lines to confirm the assemblability of their new design. During the assembly line design for new products, their engineers wore VR devices (which included over 50 sensors) and simulate the assembly work in a virtual space. During this simulation, ease of assembly operation and worker fatigue is evaluated and analyzed in real time. GM announced that by the virtual assembly simulation they had improved the assemblability of product and reduced the number of worker injuries during the manufacturing process by $70 \%$.

As Big Data technology is implemented, Product Lifecycle Management Solutions can manage and track product information from each stage of the product life such as product planning, design, development, verification, production, and after-sales-service

\subsection{Product manufacturing activity}

Most manufacturers agree that the most important target of production activities is improving and maintaining high productivity. Therefore, all production activities relate to productivity. To monitor the status of production sites, various indicators of productivity have been developed such as unit per person hour (UPPH), unit per labor cost, and utilization rate of a factory. In other words, a basic strategy to improve productivity is reducing input and/or increasing output. Especially, among productivity indicators, a key factor for increasing output is the improvement in facility utilization rate and yield.

Solutions such as predictive maintenance system (PMS) and remote control system (RCS) can increase facility utilization rate efficiently. PMS predicts machine failures before the machines actually break down. Detection algorithms in PMS make decisions based on the Big data from production locations. The remote control system monitors the conditions of the machines (equipment/facility) in a factory to prevent machine failure. Since the 1990s, many leading companies have introduced flexible manufacturing systems (FMS) to reduce production loss (model change loss) due to frequent model changes. Recently, researchers have been working on modular cell production and LEGO ${ }^{\text {TM}}$-block-type production, and combining 3D printing technology with the FMS. A smart production planning system has been developed using real time production/inventory/sales information which are necessary to obtain optimal production plans. Furthermore, many companies are developing cyber physical systems (CPS) in which digital twins of their factory are created based on facilities' real time information. Using CPS, companies are trying to operate real factory with maximum utilization rate or with maximum throughput, and success seems imminent.

Autobaulog, a German construction project, is a good example of real time optimal control based on CPS. Heavy construction equipment with sensors were deployed along the $15 \mathrm{~km}$-wide construction site, and real time information was collected from the sensors. Based on this information, a digital twin of the construction site was developed and synchronized in real time with information from the real construction site using CPS. With this CPS model, researchers are working on the decision making for optimal management of the heavy construction equipment to obtain the maximum and sustainable utilization rate.

For yield rate management, intelligent quality control solutions have been actively studied and developed. Intelligent quality control systems provide sensors and automatic control tools to adjust the process conditions according to the real time inspection data of products and status of equipment.

Fault detection and classification (FDC) collects and analyzes production data to detect and monitor faults in real time, so that lapses in quality and equipment malfunctions can be prevented in advance. Particle management systems have been widely utilized in industries in which impurities are critical issues in product quality such as semiconductor and camera lense industries.

Regarding continuous production systems, particle management has been extensively studied to improve the quality of products. For example, POSCO, one of the most advanced steel companies located in Korea, developed a smart furnace. The temperature inside the furnace is precisely controlled at $1500^{\circ} \mathrm{C}$ by monitoring the environmental conditions in/outside the furnace. Decisions are made by artificial intelligence based on big data from previous decisions and results history. Due to the automatically controlled parameters of process, it is possible to improve the uniformity of product quality, which is expected to result in an $18 \%$ improvement in the temperature deviation along the every part of furnace.

While the output of a factory is related to the yield rate, the input is closely related to cost. We can divide the cost into 4 categories: material cost, labor cost, overhead cost and an inventory holding cost. Among these costs, it is not easy to 
control the material cost only by smart factory solutions. However, as an indirect effect of smart factory solutions, the overuse of materials will be reduced if the yield rate and product quality are improved.

Modular design, a design approach that subdivides a system into smaller modules, is highly recommended to reduce the material cost and to establish flexible manufacturing system. In fact, modular design not only increases production flexibility, but also benefits from material cost savings. Honda, a global automotive company, developed a new modular platform to share strategic parts for powertrain and platform among their vehicle models. They announced that modular design will increase the component sharing rate by up to $80 \%$ and reduce costs by $20 \%$.

Smart factory solutions related to reducing labor cost is associated with factory automation. This means that human workers are replaced with automated robots in production processes. In the past, simple automation has been adopted, but the lesson from the past shows that simple automation can result in lower production flexibility. Therefore, in recent years, many companies have been actively utilizing smart working assistant systems that utilize collaborative robots to enhance work efficiency by helping human workers rather than the automation of complete unmanned operations. Since quality inspection and logistics inside factories have been associated with the lowest automation rate and highest labor costs, many companies focus on automating these activities. Logistics companies like Amazon are using smart logistics solutions that provide real time location tracking and route optimization, and many companies use intelligent defect detection systems to automate quality inspections by incorporating artificial intelligence techniques such as machine learning.

For overhead cost reduction, many companies are working to cut down electricity and fossil fuel energy use. Especially, many companies actively utilize eco-friendly energy due to the gradual strengthening of environmental regulations. The BMW factory in Leipzig has secured $70 \%$ of its energy use from wind power generation. And, cost reductions through energy saving systems are very effective especially in industries with high energy consumption such as steel, semiconductors, and display manufacturing industries. SK Telecom, a Korean telecommunications business operator, founded the energy integration control center, and has developed a smart analysis engine for energy data based on artificial intelligence to analyze the energy consumption pattern of the building. This smart analysis engine is incorporated in smart energy saving system that can derive the reduction factor and manage the power consumption prediction.

\subsection{Sales activity (including after-sales-service)}

Many companies are trying to supply not only their products but also increased customer value, so that they improve customer satisfaction by providing after-sales service before their request. To do this, they are monitoring the status of products even after sale and detecting broken products before they happen. After-sales data, such as VOCs and product usage patterns, are collected for big data analysis, and are reflected in product design and production activities to produce high quality products. During the after-service period, GE creates digital twins based on real-time sensor data transmitted from their product (aircraft engines, locomotives, gas and wind turbines) to data servers in California to monitor their products status and simulate performance. The purpose of the simulation is to predict the maintenance period and identify defects before the actual failure occurs to their customers.

\section{Smart factory application strategy according to production characteristics}

In this section, smart factory solutions are discussed and classified by characteristics of production systems. The manufacturing industry has a wide range of characteristics depending on the type of product being produced. Therefore, before the installation of a smart factory, it is necessary to determine the types of production process used for each product, and to identify steps in the implementation of a customized smart factory. There are many factors that determine the type of production process used to produce goods. Among these, the two most important factors affecting the type of the production system are the production volume and the variety of products. The original volume-variety and process matrix (Jay et al., 2016) was used to classify types of the production process depending on the volume and variety of products produced. We modified the volume and variety matrix to fit our smart factory strategy. In Figure 1, the type of production process is classified according to the volume and variety of products. Note that we exclude small-scale production because this is a production strategy that should be avoided during normal manufacturing.

There are 4 types of processes in manufacturing: Process focus, Product focus, Repetitive focus, and Mass customization focus. The features of the 4 types of process is described as follows:

- Process focus: multi-product, small-sized production

- Product focus: mass production of a few parts

- Repetitive focus: middle range process between process focus and product focus

- Mass customization focus: multi-product, large-sized production

The characteristics of each type of process and the tasks for the smart factory application are described below. Note that the examples and effects of smart solutions in Figure 1 have been discussed in Section 2. 


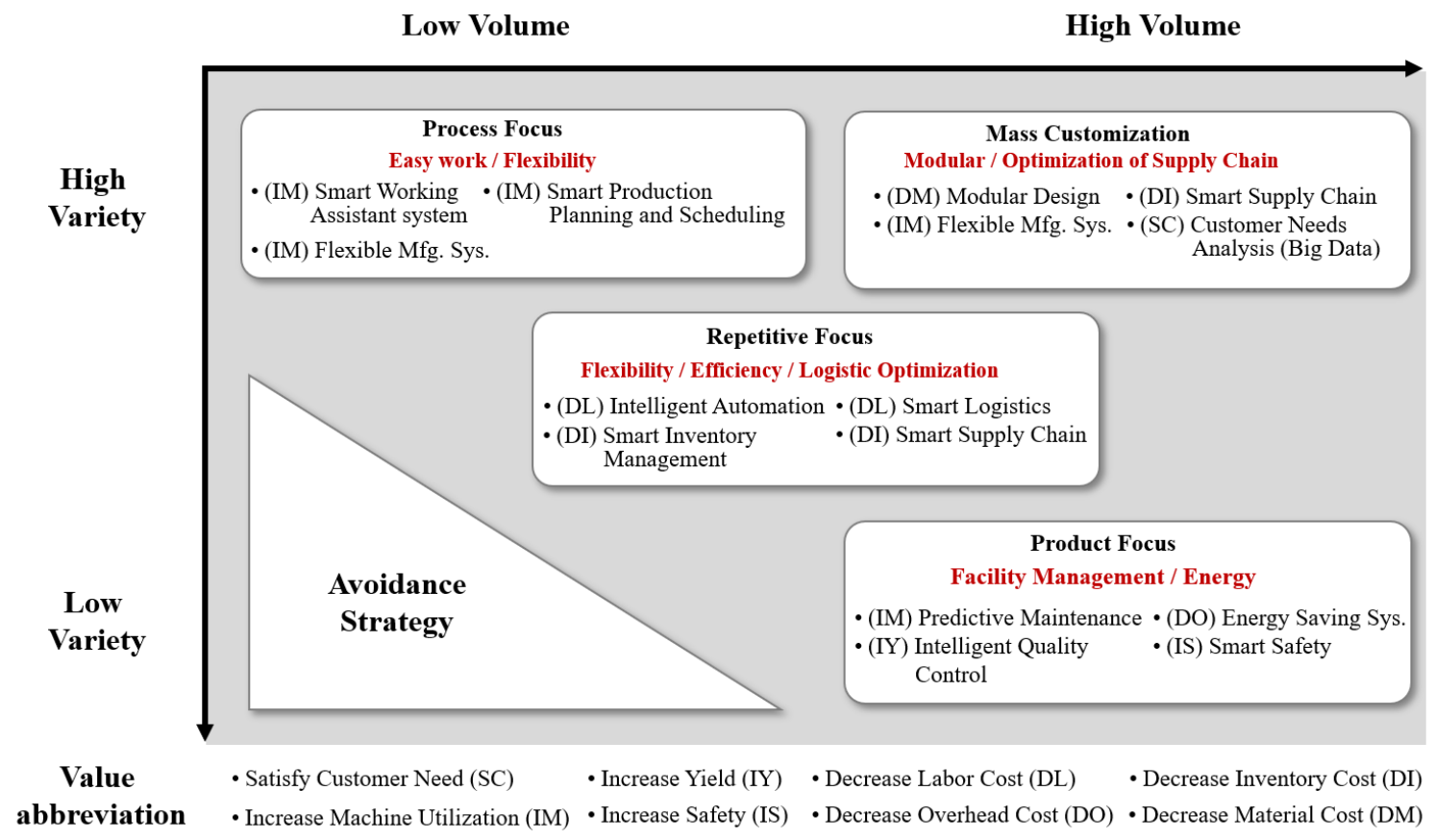

Figure 1. Key smart factory solutions by type of production systems

\subsection{Process focus process}

Process focus process type is suitable for production of high value-added and customized products. Due to the high variety of products, flexibility of process is important. In many cases of process focus manufacturing, job shop factories are common, and the utilization rate of equipment in the factory is very low (about 5 25\%). The procedure for production planning is very complex, and the production plan is inefficient. Since workers with multiple skills are needed to produce multiple types of products, the importance of workers' ability in manufacturing is higher than in other process types.

In implementing smart factories in these industries, solutions are needed to increase production flexibility and increase worker efficiency. For example, it is strongly recommended to utilize flexible production systems that feature smart manufacturing technologies such as robotics and 3D printers. The application of smart work assistance systems and smart production planning solutions are an effective way to increase overall production efficiency.

\subsection{Product focus process}

Product focus process type is characterized by industries such as petroleum, chemical, steel and cement that continuously produces a large number of highly standardized products. In these type of factories, products are produced continuously in extremely large facilities. While the roles of workers in production are relatively small, the importance of technicians to perform maintenance of facilities is high. In this type of process, it is relatively easy to form production plans, and the utilization rate of facilities is high (about 70 90\%). However, production flexibility is low and dedicated equipment is used for the production of specific products. The safety of workers is one of the most importance issues in the chemical industry, and energy consumption is very high due to the large number of facilities. Because production is continuous and installation cost is high, there occurs a lot of production losses when a machine breaks down or a product quality issue arises in production.

When a smart factory is designed for a product focus process, it is effective to apply an intelligent quality control solution that predicts abnormality of the equipment in advance and adjusts process conditions automatically by detecting defects in product quality in advance. Since most processes are energy intensive, an energy management solution is necessary to manage energy use of the plant. Also, a smart safety solution is useful to monitor worker's safety in real time and to limit risks in advance.

\subsection{Repetitive focus process}

Repetitive focus process produces a product using a general flow shop or a conveyor. This type of process applies to the automobile, computer, and home appliance industries in which components or intermediate goods from vendors are assembled and completed. Therefore, it is important to optimize the supply of components from vendors and to manage inventory. This type of process is much more reliant on workers than product focus processes. However, workers in repetitive focus process perform simpler tasks than multifunctional workers of a product focus process. Since various 
parts and semi-finished products have to be assembled on conveyer belts, material flows are easily congested with components and subsidiary materials.

To establish a smart factory for this type of process, it is effective to actively apply intelligent automation using collaborative robots that can replace low skilled workers. Also, smart logistics systems are needed to increase productivity. Smart warehouse systems will help optimize the storage allocation and manage the receipt and dispatch of multiple product items in FIFO manner. Supply chain management solutions handle the real time production and inventory information shared by vendors and synchronizes the production plan of the participants in the supply chain by increasing collaborative relationships.

\subsection{Mass customization focus manufacturing}

Multi-product mass-production is a concept that integrates mass production and customized orders. In the mass customization industry, products with greater variety of types are manufactured compared to the assembly industry. In mass production systems, inventory issues are a critical challenge since products are manufactured based on the forecasts of the customer demand. However, in multi-product production systems, production costs are inevitably higher increased due to lower production efficiency. Therefore, multi-product mass production was a production system that many companies wanted to achieve in the past. However, it success was limited by insufficient technological development. With recent advances in manufacturing technologies and the development of logistics systems, many companies are implementing large-volume production systems for various products, especially in the fashion industry.

In order to implement a mass customization focus manufacturing, it is necessary to modularize products efficiently that reflects the needs of various customers. A highly flexible manufacturing system should be established to increase the production efficiency of products. To achieve flexibility in production, state-of-the-art technology such as high-speed and high-resolution 3D printing is applied to the production line. Also, factories should utilize big data technology and virtual design solutions during the development phase to quickly analyze customer needs and incorporate them into product design. In addition, supply chain optimization solutions should be actively implemented to achieve the whole supply chain efficiency and drive collaboration with vendors and customers. The most important factor in the success of mass customization focus manufacturing is the reduction of lead time, which can be achieved by optimizing supply chains along with production flexibility. In other words, component supplier management, inventory management, production management, and delivery management must be tightly linked and optimized in mass customization focus manufacturing. Harley Davidson, even though they assemble more than 1,200 motorcycles per day, has reduced the lead time (from order to production) from 21 days to 6 hours by optimizing the supply chain and establishing a flexible production system.

\section{Conclusion}

When we try to establish a smart factory, we have to focus on our goals. A smart factory is not goal in itself. A smart factory is a tool to achieve our goals. To create a successful smart factory, it is important to make appropriate strategy by considering characteristics of the industry and the products they produce. Nowadays, the world is looking at smart factories as the fourth industrial revolution in manufacturing. We have introduced the latest smart technology trends for smart factory in this paper. In addition, we classified major solutions by value chain activity. In addition, we divided manufacturing industries into four groups according to product variety and production quantity. Then, we proposed strategies and direction for successful application of smart factories in each industry group. This study aims to provide companies important considerations in establishing smart factory operational strategies.

\section{References}

Byun, D.H., 2016. Trend of smart factory and model factory cases, The e-Business Studies 17, 211-228.

Chen, B. Wan, J. Shu, L. Li, P. Mukherjee, M., Yin, B., 2018. Smart factory of industry 4.0: key technologies, application case, and challenges, IEEE Access 6, 6505-6519.

Hozdić, E., 2015. Smart factory for industry 4.0: A review, International Journal of Modern Manufacturing Technologies, 7, 28-35.

Jay H., Barry R., Chuck M., 2016, Principles of Operations Management (10th Edition). Pearson Publishers, London, England.

Kang, H.S., Lee, J.Y., Choi, S.S., Kim, H., Park, J.H., Son, J.Y., Kim, B.H., Noh, S.D., 2016. Smart manufacturing: Past research, Present Findings, and Future Directions, International Journal of Precision Engineering and Manufacturing-Green Technology, 3, 111-128.

Lee, S.H., Kim, J.Y., Lee, W.H., 2017. Smart factory literature review and strategies for Korean small manufacturing firms, Journal of Information Technology Applications \& Management 24, 133-152.

Lim, J.W., Jo, D.H., Lee, S.Y., Park, H.J., Par, J.W., 2017. A case study for the smart factory application in the manufacturing industry. Korean Journal of Business Administration 30, 1609-1630.

Park, J., 2017. Analysis on success cases of smart factory in Korea: Leveraging from large, medium, and small size enterprises, Journal of Digital Convergence 24, 107-115.

Pearson Bagozi, A., Bianchini, D. Antonellis, V.D., Marini, A., Ragazzi, D., 2017. Summarisation and Relevance Evaluation 
Techniques for Big Data Exploration: The Smart Factory Case Study, In: Dubois, E., Pohl, K. (Eds), CAiSE 2017. LNCS 10253, 264-279. Springer, Cham.

Radziwon, A. Bilberg, A. Bogers, M. Madsen, E.S., 2014. The smart factory: Exploring adaptive and flexible manufacturing solutions, Procedia Engineering 69, 1184-1190.

Thoben, K.D., Wiesner, S., Wuest, T., 2017. "Industrie 4.0" and smart manufacturing-a review of research issues and application examples. International Journal of Automation Technology 11, 4-19.

Yang, L., 2017. Industry 4.0: A survey on technologies, applications and open research issues, Journal of Industrial Information Integration 6, 1-10.

Zhou, K., Liu, T., Zhou, L., 2015. Industry 4.0: Towards future industrial opportunities and challenges. Proceedings of 201512 th international conference on fuzzy systems and knowledge discovery, Zhangjiajie, China. 